\title{
Study of gasless compositions used in time-delay elements
}

\author{
$\mathrm{Fe} / \mathrm{BaO}_{2}$ composition
}

\author{
M. M. Gerlich ${ }^{1}$ (D) A. T. Wojewódka ${ }^{1}$
}

Received: 11 February 2019/Accepted: 16 August 2019/Published online: 30 August 2019

(C) The Author(s) 2019

\begin{abstract}
This article presents the results of burn rate measurements conducted for a $\mathrm{Fe} / \mathrm{BaO}_{2}$ pyrotechnic delay composition. Compositions with an iron content between $15 \%(\mathrm{w} / \mathrm{w})$ and $50 \%(\mathrm{w} / \mathrm{w})$ yielded burn rates in the range of 4-36 $\mathrm{mm} \mathrm{s}^{-1}$. Mixtures containing more than $50 \%(\mathrm{w} / \mathrm{w})$ iron could not be initiated by a powder fuse and are not suited for application as delay compositions. This study also presents a cost-efficient method for measuring linear combustion velocities and its application to the investigation of the $\mathrm{Fe} / \mathrm{BaO}_{2}$ composition. Thermogravimetric and XRD studies have revealed that the reactions between iron and barium peroxide take place in the solid phase, leading to the formation of varied spinels.
\end{abstract}

Keywords Time-delay composition · Gasless combustion · Time-delay detonators · Solid-state reactions

\section{Introduction}

Delay detonators play a significant role in blasting operations. As they make it possible to delay the firing of individual explosives in a blasting network, they contribute to increasing the amount of the deposit, its optimal ejection and desired fragmentation. This feature is provided by the delay element within a detonator. It consists of a pyrotechnical mixture, pressed in a metal (or polymer [1]) tube. According to the literature, the pyrotechnical mixtures come in one or more oxidants and one or more fuels. Very often, these two components are bonded together using a third component-binder [2]. Oxidants, after thermal decomposition, are the source of the oxygen, which is necessary for the combustion of a fuel. The reaction between components in this kind of compositions is not direct, as it comes in a solid-gas-solid system [3].

Electronic supplementary material The online version of this article (https://doi.org/10.1007/s10973-019-08721-8) contains supplementary material, which is available to authorized users.

\section{M. Gerlich}

marcin.gerlich@polsl.pl

1 Department of Inorganic Chemistry, Analytical Chemistry and Electrochemistry, Silesian University of Technology, Krzywoustego 6 Street, Gliwice, Poland
This fact makes the linear velocity of combustion dependent on the pressure. As a result, the burning velocity changes its value on entire length of delay element, as a detonator is a closed system. Due to this fact, application of so-called gasless pyrotechnical compositions is recommended. According to Charsley and Chen [4], the term "gasless" relates to compositions that generate up to $10 \mathrm{~cm}^{3}$ of gases per $\mathrm{g}$ of mixture. This feature limits the adverse effect of pressure on the stability of the combustion process [5].

There are two approaches to decreasing the amount of gas products generated by a pyrotechnic delay composition. The first is to increase the amount of fuel, pushing the oxygen balance towards more negative values. This approach, however often encountered, is limited both by the issues with combustion stability and reproducibility occurring for compositions with strongly negative oxygen balances and by the difficulty of maintaining the desired burn rate [6]. The second approach is to use a composition whose components burn yielding primarily solid products.

The combustion of pyrotechnic compositions takes place as solid-solid, solid-liquid and/or solid-gaseous state reactions [7]. The literature gives examples of a gasless, solid-state reaction mainly for nanopowders $[8,9]$. Also binary, iron-based compositions are most likely to react in solid/solid systems [10-13]. Numerous studies on such compositions have focused on $\mathrm{Fe} / \mathrm{BaO}_{2}$ and $\mathrm{Fe} / \mathrm{SrO}_{2}$ 
systems. Tribelhorn emphasises that the combustion of these substances can take place not only via gaseous intermediates, but also between solid substances. According to the above-mentioned report, the following reactions may take place between $\mathrm{Fe}$ and $\mathrm{BaO}_{2}$ [11]:

$$
\begin{aligned}
& 2 \mathrm{Fe}_{(\mathrm{s})}+3 \mathrm{BaO}_{2(\mathrm{~s})} \rightarrow \mathrm{Fe}_{2} \mathrm{O}_{3(\mathrm{~s})}+3 \mathrm{BaO}_{(\mathrm{s})} \\
& 3 \mathrm{Fe}_{(\mathrm{s})}+4 \mathrm{BaO}_{2(\mathrm{~s})} \rightarrow \mathrm{Fe}_{3} \mathrm{O}_{4(\mathrm{~s})}+4 \mathrm{BaO}_{(\mathrm{s})} \\
& \mathrm{Fe}_{(\mathrm{s})}+\mathrm{BaO}_{2(\mathrm{~s})} \rightarrow \mathrm{FeO}_{(\mathrm{s})}+\mathrm{BaO}_{(\mathrm{s})}
\end{aligned}
$$

Even though it has not been conclusively determined whether the above reactions take place via a $\mathrm{BaO}_{2}$ thermal decomposition stage or directly between the solid components, it was found that the products of these reactions react further in the solid state:

$$
\begin{aligned}
& \mathrm{Fe}_{2} \mathrm{O}_{3(\mathrm{~s})}+\mathrm{BaO}_{(\mathrm{s})} \rightarrow \mathrm{BaFe}_{2} \mathrm{O}_{4(\mathrm{~s})} \\
& \mathrm{FeO}_{(\mathrm{s})}+\mathrm{BaO}_{2(\mathrm{~s})} \rightarrow \mathrm{BaFeO}_{3(\mathrm{~s})} \\
& \mathrm{Fe}_{(\mathrm{s})}+2 \mathrm{BaO}_{2(\mathrm{~s})} \rightarrow \mathrm{Ba}_{2} \mathrm{FeO}_{4(\mathrm{~s})} \\
& \mathrm{FeO}_{(\mathrm{s})}+2 \mathrm{BaO}_{(\mathrm{s})}+\mathrm{BaO}_{2(\mathrm{~s})} \rightarrow \mathrm{Ba}_{3} \mathrm{FeO}_{5(\mathrm{~s})}
\end{aligned}
$$

Although the occurrence of solid-phase reactions makes the burning rate virtually independent of the pressure in the environment, it increases the susceptibility of the mixture to ageing. This property is closely related to the fact that the actual combustion process, i.e. the main exothermic reaction, is in the case of gasless compositions preceded by a series of pre-ignition reactions. These reactions reduce the contact area between the oxidising agent and fuel grains, due to the formation of solid-state products, at temperatures significantly lower than the reported ignition temperature [14]. Spice estimates that the amount of iron which reacts during the pre-ignition reactions stage may vary from 10 to $20 \%$ (w/w), depending on the loads applied for pressing the composition. This amount of reagent mass loss can significantly change the combustion parameters of the composition. Therefore, the pressing load influences both the ageing of the composition and its burn rate $[15,16]$. It was also found that the addition of ferric oxide decreases the share of oxidised iron [14]. Binders also decrease the contact area between the fuel and the oxidant, reducing ageing, which is why gasless mixtures should be ternary mixtures.

Susceptibility to ageing necessitates subjecting gasless mixtures to a stabilisation process. The stabilisation process typically consists of conditioning the composition at an elevated temperature, for an extended period, such as a week. The stabilisation process is meant to accelerate the ageing processes to an extent that the solid-state products of the pre-ignition reactions create a barrier between components of the composition, stopping further ageing. By making use of this process, we can ensure that the burning rates of a particular composition will be consistent and stable over time.

The aim of this manuscript is to present the dependence of the linear velocity of $\mathrm{Fe} / \mathrm{BaO}_{2}$ composition combustion on the share of the components of the composition. Investigations into the nature of the reactions occurring during the combustion of the composition are also shown, focusing on XRD and differential thermal analyses.

\section{Experimental}

\section{Materials}

Carbonyl iron $(98 \%(\mathrm{w} / \mathrm{w})$ purity, main contaminants were $\mathrm{C}<1 \%$ (w/w), $\mathrm{O}<1 \%(\mathrm{w} / \mathrm{w})$ and $\mathrm{B}<30 \mathrm{mg} \mathrm{kg}^{-1}$ ) obtained from KKM Poland was used without purification. Barium peroxide $(99.3 \%$ (w/w) purity, main contaminants were $\mathrm{H}_{2} \mathrm{O}<0.1 \%$ (w/w)) obtained from Krakchemia S.A. was used without purification. The particle size distribution of both components was investigated using laser particle sizer Analysette 22 NanoTec, and the results are presented in Table 1. The general morphology of barium peroxide (Fig. 1a) and carbonyl iron (Fig. 1b), along with the dimensions of their particles, was investigated by SEM, using a Phenom Pro-X microscope, manufactured by Phenom World.

The $d_{4.3}, d_{3.2}$ and $d_{1.0}$, shown in Table 1 mean:

$d_{4.3}$-volume moment mean (Sauter mean diameter)

$d_{3.2}$-surface area moment mean (De Brouckere mean diameter)

$d_{1.0}$-arithmetic mean

\section{Delay fuse preparation}

The delay elements were produced using 30-cm-long $\mathrm{Pb}-$ $\mathrm{Sb}$ alloy $(99 \%(\mathrm{w} / \mathrm{w}) \mathrm{Pb})$ tubes. The tubes had an outer diameter of $16 \mathrm{~mm}$ and an inner diameter of $11 \mathrm{~mm}$. Preparation of the composition consisted of drying the oxidant for $24 \mathrm{~h}$ in temperature of $60{ }^{\circ} \mathrm{C}$, then both the components were mixed manually in a desirable ratio.

Delay fuses were prepared by drawing lead tubes, filled with a particular $\mathrm{Fe} / \mathrm{BaO}_{2}$ composition with bulk density, by dragging the sealed tubes through a set of eyelets, with a

Table 1 Grain characteristics of $\mathrm{Fe}$ and $\mathrm{BaO}_{2}$

\begin{tabular}{llll}
\hline & $d_{4,3} / \mu \mathrm{m}$ & $d_{3,2} / \mu \mathrm{m}$ & $d_{1,0} / \mu \mathrm{m}$ \\
\hline $\mathrm{Fe}$ & 7.94 & 4.96 & 0.44 \\
$\mathrm{BaO}_{2}$ & 8.43 & 2.51 & 0.09 \\
\hline
\end{tabular}




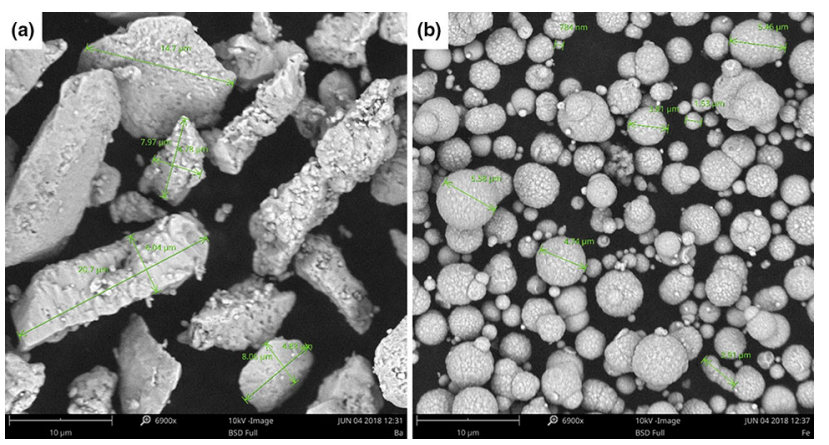

Fig. 1 SEM photographs of $\mathrm{BaO}_{2}$ (a) and carbonyl iron (b)

smaller nominal inner diameter, than the outer diameter of the lead tube. This process produced tubes that were approximately $2 \mathrm{~m}$ long, had an outer diameter of $6 \mathrm{~mm}$ and were filled with $\mathrm{Fe} / \mathrm{BaO}_{2}$ composition, which was pressed during this process. The drawn tubes, filled with the pressed delay composition, were then cut into $19-\mathrm{cm}-$ long samples. These samples have all been labelled with the iron content of the loaded composition and their original position in the 2-m-long delay fuse. Taking into account the collection of the fuse parts for density studies, more than eight speed test samples were obtained for compositions with each of the investigated iron content values.

\section{Time-delay measurements}

The linear velocity of combustion was measured using a short circuit system, consisting of copper wires $(d=0.07 \mathrm{~mm})$ and an Arduino Leonardo microcontroller board. Every delay fuse sample was divided into five sections: a run-up section, three measurement sections and an ending section (as shown in Fig. 2).

For each investigated $19-\mathrm{cm}$ sample, the three measurement sections were delimited by four measurement points. Each measurement point in the short circuit system, consisted of a pair of insulated copper wires, wrapped around each other. The wires were woven through prepared 1-mm-thick holes in the lead tube. When the front of combustion reaches a particular measurement point, the insulation coating the wires would be burnt, allowing the flow of current, which was induced by the $5 \mathrm{~V}$ potential difference, applied by the microcontroller board to one wire of each pair. Appearance of the current signal for the first probe can be easily interpreted by the microcontroller board, as a moment for starting counting the elapsed time. This feature can be achieved by a program written in the $\mathrm{C}++$ language that is compatible with Arduino boards. Written program specified current signals that come from the other three probes, as a request to show time-delay results. Thus, for every $19-\mathrm{cm}$-long sample, three results of velocity were obtained.

\section{X-ray diffraction studies}

The qualitative composition of combustion products has been determined by using a Philips X-ray diffractometer (model X'Pert), using a lamp with a copper anode $(\lambda \mathrm{CuK} \alpha=1.54178 \AA$ ), supplied with a current of $30 \mathrm{~mA}$ and voltage of $40 \mathrm{kV}$. The scans were taken with a 20 -s dwell time in step-scan mode with step size of $0.04^{\circ}$ and $2 \Theta$ in the range of $10^{\circ}-140^{\circ}$. XRD analyses of combustion products lasted for $24 \mathrm{~h}$ for each sample and were conducted in air.

\section{Sleeve thickness measurement}

Ultrasonic defectoscopy (DMS Go+ type flaw detector, produced by Measurements \& Control) was used to determine the wall thickness of the prepared delay fuses. Due to the small diameter of the samples, a DA312 B16 gauging probe was used for this purpose. The generated acoustic signal was $84.4 \mathrm{~dB}$ with frequency of $10 \mathrm{MHz}$.

\section{DTA and TG analysis}

Differential thermal analysis and thermogravimetric analyses of $\mathrm{BaO}_{2}$ and $\mathrm{Fe} / \mathrm{BaO}_{2}$ composition (with $45 \%$ and

Fig. 2 3D model of fuse sample with probes

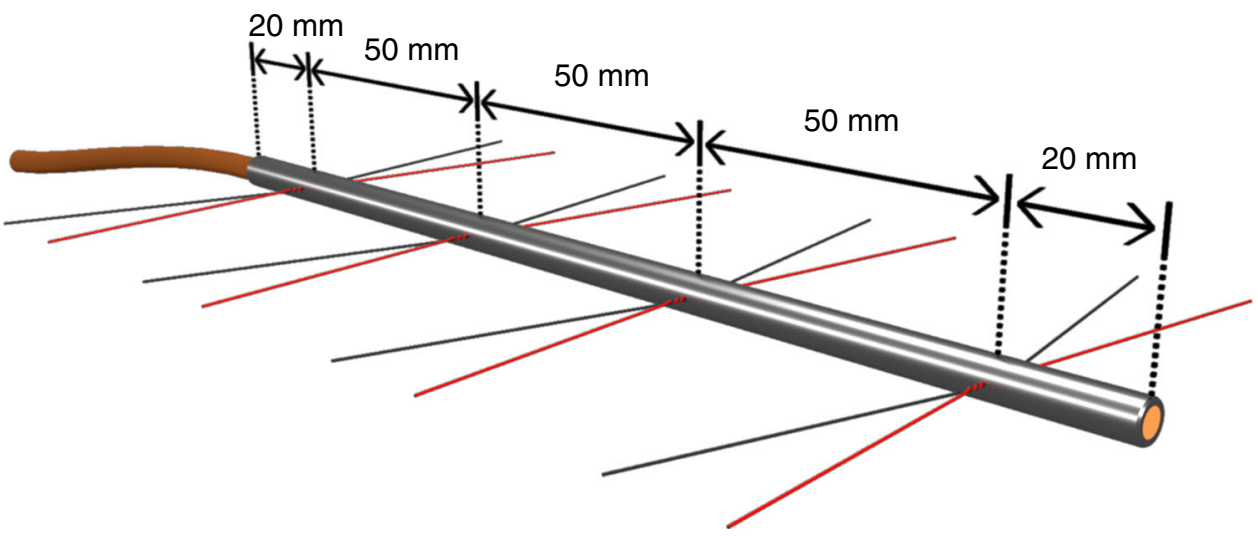


$50 \%(\mathrm{w} / \mathrm{w})$ iron content) were conducted using MOM Q1500D derivatograph. These compositions were selected based on their favourable burn rate measurement results. All samples were tested in amounts of approximately $1 \mathrm{~g}$, in a temperature range from 300 to $1270 \mathrm{~K}$, with a temperature scanning rate of $10 \mathrm{~K} \mathrm{~min}^{-1}$. It was assumed that data considering the current mass of the sample could be collected using a range of $500 \mathrm{mg}$, with aluminium oxide as the reference sample. All analyses were performed in argon.

\section{Mixture sensitivity}

In order to determine the sensitivity of the mixture to impact, the BAM Fallhammer test was used (according to EN 13631-4:2004) [17]. Determination of the sensitivity of the mixture to friction was made in accordance with the EN 13631-3:2004, using the Peters friction apparatus [18].

\section{Results and discussion}

\section{Parameters of delay element}

The softness of the lead alloy makes it difficult to cut the delay element without affecting its lateral dimensions. Consequently, ultrasonic defectoscopy, a non-destructive method, was used to measure sleeve thicknesses.

The results of composition density and sleeve thickness measurements for each composition with a given iron content have been averaged for all produced $19-\mathrm{cm}$ samples and are collated in Table 2.
Table 2 Results of mixture density and sleeve thickness measurements

\begin{tabular}{lll}
\hline$\% \mathrm{Fe}$ & Density/g cm & Wall thickness $/ \mathrm{mm}$ \\
\hline 15 & 3.1 & 1.16 \\
20 & 3.3 & 1.18 \\
25 & 3.2 & 1.12 \\
30 & 3.4 & 1.10 \\
35 & 3.3 & 1.09 \\
40 & 3.5 & 1.11 \\
45 & 3.5 & 1.10 \\
50 & 3.8 & 1.09 \\
\hline
\end{tabular}

\section{Burning rates of the investigated compositions}

The 19-cm samples containing the composition with the same iron content have been grouped together. In these groups, each $19-\mathrm{cm}$ sample provided three burning rate data points over its length as shown in Fig. 2. By ordering sets of data points from each $19-\mathrm{cm}$ sample by the original position of the sample in the uncut 2-m-long delay fuse, we were able to recreate the changes in the burning rate of the composition across the entire length of the 2-m delay fuses, for compositions with each investigated iron content (Fig. 3).

The lowest burning rate standard deviation values are found for compositions rich in iron, i.e. exhibiting low oxygen balance values. Although increasing the iron content stabilises the burn rate, compositions consisting of more than $50 \%(\mathrm{w} / \mathrm{w})$ iron become insensitive to ignition with a black gunpowder fuse. The findings of the presented research, which includes the standard deviation and variance of burn rate, are illustrated in Table 3 .
Fig. 3 Comparison of burn rates of iron-based compositions with different iron contents

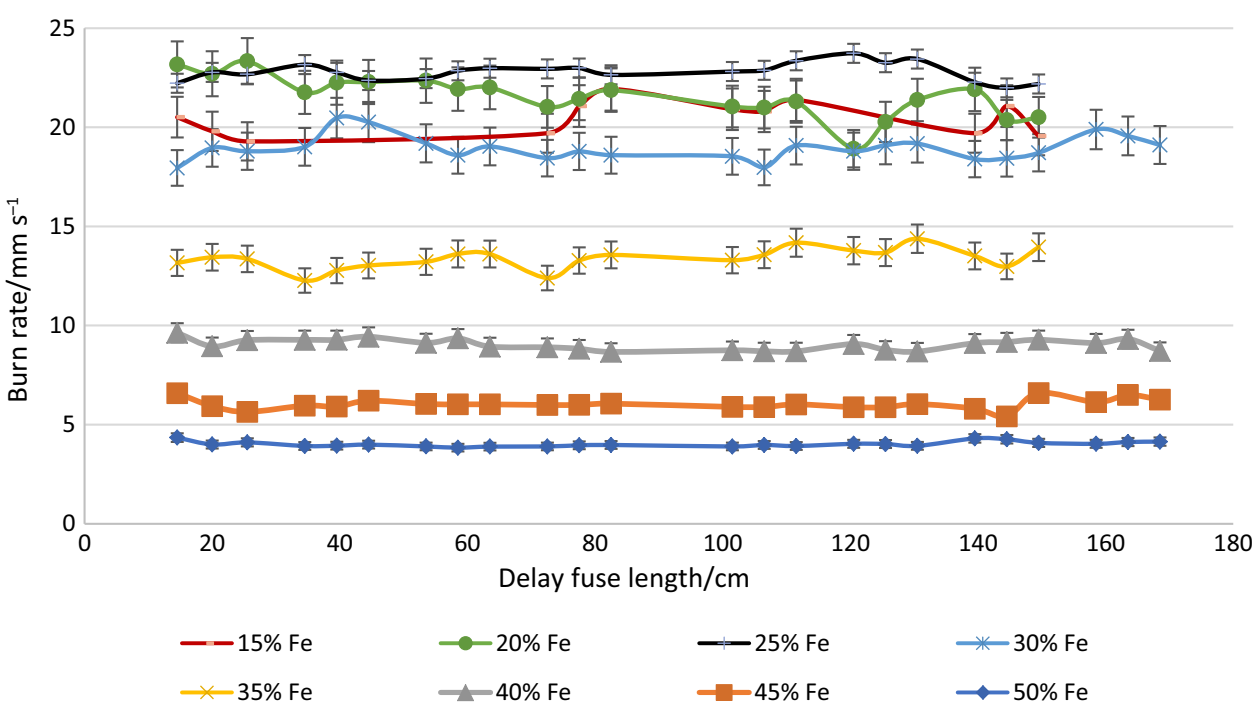


Table 3 Standard deviation and limit values of $\mathrm{Fe}-\mathrm{BaO}_{2}$ composition burn rate

\begin{tabular}{llll}
\hline $\begin{array}{l}\text { Iron } \\
\text { content/\% }\end{array}$ & $\begin{array}{l}\text { Minimum burn } \\
\text { rate/mm s }\end{array}$ & $\begin{array}{l}\text { Maximum burn } \\
\text { rate/mm s }\end{array}$ & $\begin{array}{l}\text { Standard } \\
\text { deviation } / \mathrm{mm} \mathrm{s}^{-1}\end{array}$ \\
\hline 15 & 18.29 & 22.94 & 1.22 \\
20 & 18.92 & 23.33 & 1.01 \\
25 & 21.99 & 23.73 & 0.48 \\
30 & 17.95 & 20.47 & 0.59 \\
35 & 12.27 & 14.38 & 0.50 \\
40 & 8.67 & 9.63 & 0.28 \\
45 & 5.42 & 6.60 & 0.25 \\
50 & 3.84 & 4.35 & 0.14 \\
\hline
\end{tabular}

The dependence of the average burning rate on the iron content in the composition is shown in Fig. 4.

The highest burning rate is observed for a composition containing $25 \%(\mathrm{w} / \mathrm{w})$ iron. Lowering the fuel content in the composition significantly increases the standard deviation of burn rate values. The oxygen balance of these two compositions (with $15 \%$ and $20 \%(\mathrm{w} / \mathrm{w})$ iron content) is likely negative, as the stoichiometric content of iron, depending on whether reaction (1), (2) or (3) is assumed, would respectively, be $15.8 \%, 17.4 \%$ and $21.9 \%(\mathrm{w} / \mathrm{w})$ [15]. This fact describes the variation in the burn rate results compositions with low iron content.

\section{DTA and TG analysis}

The results of thermogravimetric studies of barium peroxide are shown in Fig. 5. The initial mass loss of the sample, seen at temperatures below $120{ }^{\circ} \mathrm{C}$, occurs due to the loss of moisture. Tribelhorn reports that water content above $1 \%(\mathrm{w} / \mathrm{w})$ in the $\mathrm{Fe} / \mathrm{BaO}_{2}$ mixture causes the combustion process to fail [11]. Therefore, it seems reasonable to determine the presence of water in the mixture in any form-especially in the form of barium peroxide hydrates. No further sample mass decrease is seen below $580{ }^{\circ} \mathrm{C}$, indicating that no significant amounts of barium peroxide hydrates are present in the sample.
The thermal decomposition of barium peroxide has an onset at approximately $580{ }^{\circ} \mathrm{C}$, with the endothermic peak maximum being observed at approximately $820{ }^{\circ} \mathrm{C}$. The endothermic effect at this temperature may arise not only from the thermal decomposition of barium peroxide, but also from the endothermic phase transition of barium carbonate [19], which is a common barium peroxide contaminant. However, XRD analysis of $\mathrm{BaO}_{2}$ sample did not show the presence of this compound.

As the thermal decomposition of barium peroxide is a highly endothermic reaction (as established from the differential thermal analysis shown in Fig. 5), the energy generated from solid-state reactions between barium peroxide and iron/iron oxides is consumed to decompose the oxidising agent. For this reason, the amount of energy transferred to the further layers of the system is insufficient to ensure the stability of combustion front propagation.

The initial mass of the $\mathrm{BaO}_{2}$ sample was $1001.7 \mathrm{mg}$, with the purity of $95 \%(\mathrm{w} / \mathrm{w})$, as given by the manufacturer. XRD investigation revealed that, apart from possible contaminants, whose concentration was below the detection threshold of the XRD set-up (vide infra), the purity of the sample was approximately $98 \%$ (on the basis of change in mass of the sample resulting from the thermal decomposition of $\mathrm{BaO}_{2}$ ). Performing analyses that excluded the presence of $\mathrm{BaO}$ and $\mathrm{Ba}(\mathrm{OH})_{2}$ in the sample and determining the temperature of $\mathrm{BaO}_{2}$ decomposition, thermogravimetric analysis of the mixture discussed in this article was performed, the results of which are shown in Figs. 6 and 7.

Figures 6 and 7 both feature a large exothermic peak in the range of $500-600{ }^{\circ} \mathrm{C}$, in both cases, the maximum is at $540{ }^{\circ} \mathrm{C}$. It is important to note that the total mass of the sample changes only very slightly (by less than $0.5 \%$ (w/ w)) across the entire temperature range. This indicates that no gaseous products are leaving the system during the reaction. Seeing that decomposition of $\mathrm{BaO}_{2}$ takes place at approximately $820{ }^{\circ} \mathrm{C}$ and is an endothermic process, the presence of the oxygen in this system can be excluded. In the light of this, we can attribute the presence of the exothermic peak at $540{ }^{\circ} \mathrm{C}$ to the solid-phase reaction
Fig. 4 The effect of iron content on composition burn rate

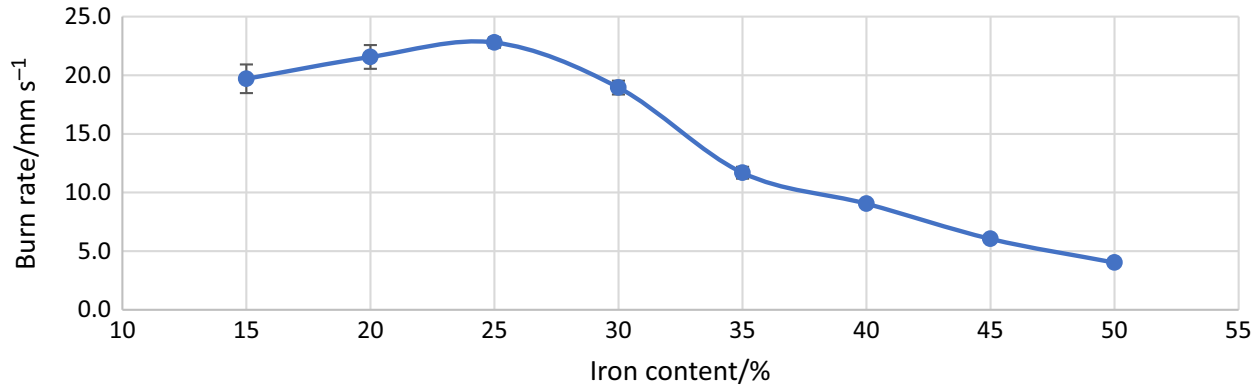




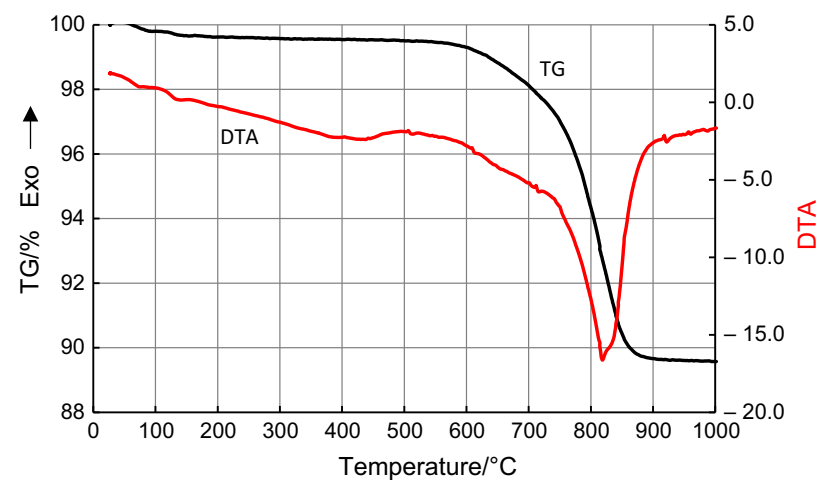

Fig. $5 \mathrm{TG}$ and DTA of barium peroxide, heated at $10{ }^{\circ} \mathrm{C} \min ^{-1}$ in air

between $\mathrm{Fe}$ and $\mathrm{BaO}_{2}$. It was therefore confirmed that no gaseous intermediates appear during the reaction. Interestingly, a portion of $\mathrm{BaO}_{2}$ present in the sample of the composition did not take part in the solid-phase reaction. This is evidenced by the presence of a minor endothermic peak seen at approximately $820{ }^{\circ} \mathrm{C}$, attributed to the thermal decomposition of $\mathrm{BaO}_{2}$ (Fig. 5).

\section{X-ray diffraction analysis}

The results of XRD analyses indicate that the sample is not contaminated with any detectable amounts of barium hydroxide, barium oxide or barium carbonate. Despite the fact that the literature indicates that the content of barium carbonate up to $10 \%(\mathrm{w} / \mathrm{w})$ in the mixture does not affect the mass burning process [7], special attention had been paid to the content of any additives in the oxidiser sample, due to the possibility of reducing its contact surface with fuel, which may cause the reaction in the solid phase to stop in favour of reactions with gaseous intermediates.

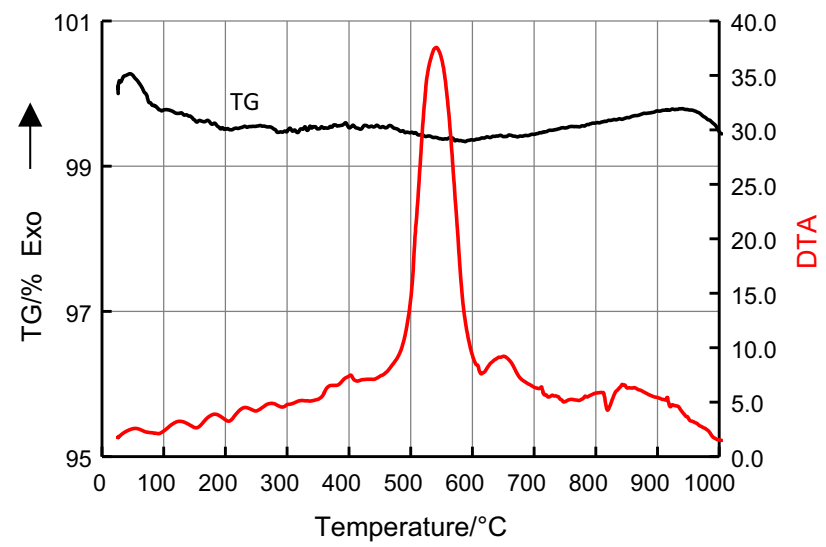

Fig. 6 TG and DTA of reaction products of the sample with $45 \% \mathrm{Fe}$ $(\mathrm{w} / \mathrm{w})$ in $\mathrm{Ar}$

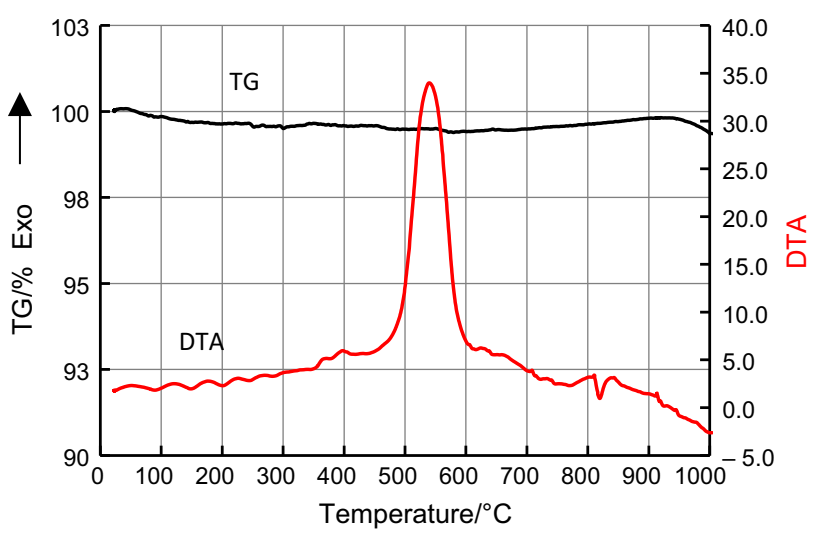

Fig. 7 TG and DTA of reaction products of the sample with $50 \% \mathrm{Fe}$ (w/w) in Ar

Analysis of the products of combustion of a composition containing 20\% (w/w) Fe reveals the presence of $\mathrm{Ba}_{3} \mathrm{Fe}_{2}$ $\mathrm{O}_{6}, \mathrm{BaFe}_{2} \mathrm{O}_{4}, \mathrm{BaFeO}_{4}, \mathrm{Fe}_{3} \mathrm{O}_{4}$ and unreacted iron. No signals corresponding to either unreacted $\mathrm{BaO}_{2}$ or $\mathrm{BaO}$ were present, indicating that barium is present only in the form of mixed oxides with iron.

It is worth noting that $\mathrm{Ba}_{3} \mathrm{Fe}_{2} \mathrm{O}_{6}$ and $\mathrm{BaFeO}_{3}$ have been identified among the combustion products, in conjunction with other products reported in the literature [7]. Consequently, the set of reactions that may occur in the system should be extended to include these two products. The possible reactions leading to the formation of $\mathrm{Ba}_{3} \mathrm{Fe}_{2} \mathrm{O}_{6}$ and $\mathrm{BaFeO}_{3}$, respectively, would be:

$\mathrm{Fe}_{2} \mathrm{O}_{3(\mathrm{~s})}+3 \mathrm{BaO}_{(\mathrm{s})} \rightarrow \mathrm{Ba}_{3} \mathrm{Fe}_{2} \mathrm{O}_{6(\mathrm{~s})}$

$\mathrm{FeO}_{(\mathrm{s})}+\mathrm{BaO}_{2(\mathrm{~s})} \rightarrow \mathrm{BaFeO}_{3(\mathrm{~s})}$

Analysis of combustion products of mixture with $40 \%$ iron content indicates the presence of following compounds: $\mathrm{Ba}_{3} \mathrm{Fe}_{2} \mathrm{O}_{6}, \mathrm{BaFeO}_{3}, \mathrm{Fe}, \mathrm{Fe}_{3} \mathrm{O}_{4}, \mathrm{BaFe}_{2} \mathrm{O}_{4}$ and $\mathrm{BaFeO}_{4}$, while the combustion of the mixture with $50 \%$ iron content was accompanied by the following compounds: $\mathrm{Fe}, \mathrm{BaFeO}_{3}, \mathrm{Ba}_{2} \mathrm{Fe}_{2} \mathrm{O}_{5}, \mathrm{BaFeO}_{4}, \mathrm{Fe}_{3} \mathrm{O}_{4}$ and $\mathrm{BaFe}_{2} \mathrm{O}_{4}$. Both of the above analyses indicate the presence of barium carbonate in the products. However, due to the lack of a binder in the mixture (which could be a source of carbon), the presence of barium carbonate in the reaction products is highly questionable and most likely results from the large convergence of the diffraction reflections of the two compounds with subsequent erroneous assignment by the database of these reflections for barium carbonate.

\section{Sensitivity testing}

The composition in the entire range of investigated iron contents is insensitive to friction $(>360 \mathrm{~N})$ and impact 
(> $50 \mathrm{~J})$. Consequently, the $\mathrm{Fe} / \mathrm{BaO}_{2}$ composition cannot be classified as a flammable mixture [20].

\section{Conclusions}

The main purpose of this work was to determine the propagation rate of the reaction front in a wide range of iron contents in the $\mathrm{Fe} / \mathrm{BaO}_{2}$ mixture. As the delay elements were made by the drawing method, the delay composition was pressed in situ; hence, the pressing load determination is not possible. Using the presented methodology, it was possible to obtain the delay fuses whose burning rates were in the range of $4.0-23.0 \mathrm{~mm} \mathrm{~s}^{-1}$. The highest burning rate was achieved for the composition with $25 \%(w / w)$ iron content. Compositions with more positive oxygen balance values (iron content of $15 \%$ and $20 \%(\mathrm{w} / \mathrm{w}))$ show slightly lower burning rates $(21.0$ and $21.5 \mathrm{~mm} \mathrm{~s}^{-1}$, respectively). Their combustion, however, is strongly dependent on many parameters (degree of mixing, grain characteristic) that even minor change strongly affects burning rates. The lowest standard deviations of burning rates as well as the lowest burning rates were seen for compositions with the most negative oxygen balance values $(45 \%$ and $50 \%(\mathrm{w} / \mathrm{w})$ iron content). The compositions, which are all insensitive to friction $(>360 \mathrm{~N})$ and impact $(>50 \mathrm{~J})$, regardless of the iron content, have been also found to become insensitive to ignition via black powder fuse when their iron content was above $50 \%(\mathrm{w} / \mathrm{w})$.

In terms of the combustion reaction, the $\mathrm{Fe} / \mathrm{BaO}_{2}$ composition was found to primarily undergo combustion via direct reactions in the solid phase. This fact is supported by thermogravimetric analyses (Figs. 6, 7). The energy transfer in the studied system is closely related to the solid-state reaction occurring at a temperature of about $540{ }^{\circ} \mathrm{C}$. At this temperature, the strongest exothermic effect was noted during thermogravimetric studies.

Acknowledgements The authors of this publication would like to express their deep gratitude to Nitroerg S.A. for providing research material, as well as for Technical and Commercial Office Testing Sp z o.o. and Ph.D. Grzegorz Dercz from Silesian University for making the necessary equipment available.

Open Access This article is distributed under the terms of the Creative Commons Attribution 4.0 International License (http://creative commons.org/licenses/by/4.0/), which permits unrestricted use, distribution, and reproduction in any medium, provided you give appropriate credit to the original author(s) and the source, provide a link to the Creative Commons license, and indicate if changes were made.

Funding This research did not receive any specific grant from funding agencies in the public, commercial or not-for-profit sectors.

\section{References}

1. Beck MW, Brown ME. Modification of the burning rate of antimony/potassium permanganate pyrotechnic delay compositions. Combust Flame. 1986;66(1):67-75.

2. McLain JH. Pyrotechnics: from the viewpoint of solid state chemistry. Philadelphia: Franklin Institute Press; 1980.

3. Zhang $\mathrm{H}$, et al. Study on the reaction mechanism between $\mathrm{Pb}_{3} \mathrm{O}_{4}$ and $\mathrm{Si}$ in stored silicon delay composition. J Therm Anal Calorim. 2018;132(1):327-36.

4. Charsley EL, et al. Differential thermal analysis and temperature profile analysis of pyrotechnic delay systems: ternary mixtures of silicon, boron and potassium dichromate. Thermochim Acta. 1980;35(2):141-52.

5. Focke WW, et al. Review of gasless pyrotechnic time delays. Propellants Explos Pyrotech. 2018;43:1-40.

6. Berger B. Parameters influencing the pyrotechnic reaction. Propellants Explos Pyrotech. 2005;30(1):27-35.

7. Moghaddam AZ, Rees GJ. Thermoanalytical studies on pyrotechnic reactions. Sci Iran. 2003;10:267-72.

8. Shuck CE, Manukyan KV, Rouvimov S, Rogachev AS, Mukasyan AS. Solid-flame: experimental validation. Combust Flame. 2016;163:487-93.

9. Korchagin MA, Gabdrashova SE, Dudina DV, et al. Combustion characteristics and structure of carbon nanotube/titanium composites. J Therm Anal Calorim. 2019. https://doi.org/10.1007/ s10973-019-08109-8.

10. Brown ME, Tribelhorn MJ, Blenkinsop MG. Use of thermomagnetometry in the study of iron-containing pyrotechnic systems. J Therm Anal Calorim. 1993;40(3):1123-30.

11. Tribelhorn MJ, Blenkinsop MG, Brown ME. Combustion of some iron-fuelled binary pyrotechnic systems. Thermochim Acta. 1995;256(2):291-307.

12. Hardt AP, Phung PV. Propagation of gasless reactions in solidsI. Analytical study of exothermic intermetallic reaction rates. Combust Flame. 1973;21(1):77-89.

13. Spice JE, Staveley LA. The propagation of exothermic reactions in solid systems, Part II. Heats of reaction and rates of burning. J Soc Chem Ind. 1949;68(12):348-55.

14. Spice JE, Staveley LA. The propagation of exothermic reactions in solid systems. Part I. Pre-ignition reactions. J Soc Chem Ind. 1949;68(11):313-9.

15. Wojewódka AT. Decysekundowe masy opóźniające. Silesian University of Technology; 2014.

16. Gromov D, et al. The influence of compression conditions on the peculiarities of self-propagating exothermal reaction in $\mathrm{Al}-\mathrm{Ni}$ powder reactive materials. $\mathrm{J}$ Therm Anal Calorim. 2018;134(1):35-44.

17. Explosives for civil uses-high explosives-part 4: determination of sensitiveness to impact of explosives (in Polish). Polish Standard PN-EN 2004;13631-4.

18. Explosives for civil uses-high explosives-Part 3: determination of sensitiveness to friction of explosives (in Polish). Polish Standard PN-EN 2004;13631-3.

19. Gruver RM. Differential thermal-analysis studies of ceramic materials: I, characteristic heat effects of some carbonates. J Am Ceram Soc. 1950;33(3):96-101.

20. United Nations. UN recommendations on the transport of dangerous goods. Model regulations. Geneva: United Nations; 2015.

Publisher's Note Springer Nature remains neutral with regard to jurisdictional claims in published maps and institutional affiliations. 